\title{
Modality and Metaphysics in Kant ${ }^{1}$
}

Toni Kannisto, University of Oslo

\section{Introduction}

Kant's theory of modality is one of the most overlooked and underrated aspects of his philosophy. Most Kant-commentators do not even hint at such a theory, and the amount of dedicated studies is unimpressive to say the least. ${ }^{2}$ Yet, Kant not only has a coherent and rigorous theory of modality, but he was also interested in modality throughout his career and gave it an important role in several key-passages of his philosophy. Indeed, it is instructive to consider his following words:

No one has ever been able to define possibility, existence, and necessity except through obvious tautologies if he wanted to draw their definition solely from the pure understanding. For the deception of substituting the logical possibility of the concept (since it does not contradict itself) for the transcendental possibility of things (where an object corresponds to the concept) can deceive and satisfy only the inexperienced. ${ }^{3}$

This is harsh critique, to be sure, as Kant considered his predecessors to be guilty of this error. ${ }^{4}$ The two-fold structure of modality to which Kant here points is itself a central tenet of his philosophy and is found at the very core of it, in the famous tables of judgments and categories. In this article I will accordingly present Kant's dual-layered theory of modality as well as consider one of its many applications, namely its essential role in his critique of metaphysics.

\footnotetext{
${ }^{1}$ The English translations of Kritik der reinen Vernunft are from Guyer, Paul and Wood, Allen W.: Critique of Pure Reason. Cambridge 1998. The English translations of Jäsche Logik are from J. Michael Young: Lectures on Logic. Cambridge 1992.

2 Some notable monographs are Schneeberger, Guido: Kants Konzeption der Modalbegriffe, Basel 1952; Grünewald, Bernward: Modalität und empirisches Denken, Eine kritische Auseinandersetzung mit der Kantischen Modalitheorie, Hamburg, 1986; and Motta, Giuseppe: Kants Philosophie der Notwendigkeit, Frankfurt (Main), 2007.

${ }^{3} \mathrm{KrV}$, A 244/B 302.

${ }^{4}$ Due to my more systematic approach, here I will not consider the historical background or development of Kant's theory of modality. For those interested in such I can recommend Motta, Giuseppe: Kants Philosophie der Notwendigkeit, Frankfurt (Main), 2007.
} 


\section{Kant's Dual-layer Theory of Modality}

The first thing to show when considering Kant's theory of modality is that he has one to begin with. What Kant says about modality is admittedly convoluted and spread somewhat haphazardly throughout his works, but luckily there is at least one solid core that provides a starting point. It is the already mentioned fact that there are two species of modality, found in the Table of Judgments and of Categories. ${ }^{5}$ I will call them judgmental and categorical modality, respectively.

Table of Judgments

$\begin{array}{lll}\text { Quantity: } & \text { Universal } & \text { Unity } \\ & \text { Particular } & \text { Plurality } \\ & \text { Singular } & \text { Totality } \\ \text { Quality: } & \text { Affirmative } & \text { Reality } \\ & \text { Negative } & \text { Negation } \\ & \text { Infinite } & \text { Limitation } \\ \text { Relation: } & \text { Categorical } & \text { Inherence and Subsistence (substantia et accidens) } \\ & \text { Hypothetical } & \text { Causality and Dependence (cause and effect) } \\ & \text { Disjunctive } & \text { Community (reciprocity between agent and patient) } \\ \text { Modality: } & \text { Problematic } & \text { Possibility - Impossibility } \\ & \text { Assertoric } & \text { Existence - Non-existence }\end{array}$

According to Kant, the modality of a judgment concerns the value of its copula, that is, the strength of the connection between the representations combined in the judgment. A problematic judgment represents this connection as merely possible, an assertoric one as actual and an apodictic as necessary. Kant also states this in terms of possible, actual and apodictic truth. Since it regulates truth, judgmental modality can be called modality of truth. Now, as judgmental modality concerns only relations among representations, and not the possible objects of these representations, it is according to Kant merely logical modality of thinking. ${ }^{6}$ (Thinking is defined as connecting representations.) Thus, importantly, judgmental modality as such is not objective.

From this arises a crucial distinction between the two types of modality. Namely, categorical modality concerns the relationship between a concept and its object. Thus, whereas judgmental modality is modality of truth, categorical modality is modality of existence. That is, the latter

\footnotetext{
${ }^{5} \mathrm{KrV}, \mathrm{A} 70 / \mathrm{B} 95, \mathrm{~A} 80 / \mathrm{B} 106$.

${ }^{6}$ Cf. e.g. KrV, A 74-76/B 99-101; Log, AA 9: 50-53, 108f.
} 
determines whether a thing corresponding to a concept exists merely possibly, actually or even necessarily. ${ }^{7}$ In contrast to the mere logical judgmental modality, categorical modality Kant also calls real or transcendental modality. This important difference can also be expressed by considering two uses of the word 'is': as copula in 'A is B', and as denoting existence in ' $\mathrm{x}$ is'.

Even at the outset it should be remarked that these two modalities are not completely separate. Since according to Kant "the understanding can make no other use of [concepts] than that of judging by means of them", the demarcation is not only between truth and existence but also between two kinds of truth: one in which the existence of the object is not considered, and the other in which it is (via categorical modality). The former kind of truth Kant calls "formal," the latter "material". While for formal truth modality of judgments is enough, material truth requires both judgmental and categorical modality. Thus we have three cases: mere judgmental modality for formal truth, mere categorical modality for existence and judgmental plus categorical modality for material truth. As an example, consider the judgment "unicorns are one-horned." As analytic, the judgment is apodictic or necessarily true, yet does not alone say anything about the possible existence of unicorns. In order to assess the latter, categorical modality has to be considered in addition to mere judgmental modality. ${ }^{10}$

To summarise, consider Kant's view of how cognition is born. First intuitions are synthesised under concepts based on similarities among them. Second, concepts are synthesised in judgments. Here judgmental modality regulates the synthesis of concepts in judgments, whereas categorical modality regulates the synthesis of intuitions under concepts. From this we see that they operate on two different levels and should thus be strictly separated. [Expand? Relocate?]

Now, the division between formal and material truth is very central in Kant's critique of metaphysics, as it marks the distinction between general and transcendental logic. General logic,

\footnotetext{
${ }^{7} \mathrm{Cf} . \mathrm{KrV}, \mathrm{A} 218 \mathrm{ff} / \mathrm{B} 265 \mathrm{ff}$.

${ }^{8} \mathrm{KrV}, \mathrm{A} 68 / \mathrm{B} 93$.

${ }^{9}$ Log, AA 09: 50-53.

10 This does not contest Kant's view that also analytic judgments are related to objects. All concepts purport to refer to objects, but for Kant no mere analysis of concepts is sufficient for determining whether their referents are possible, actual or necessary. For this, categorical modality is needed. (An analysis of a concept may show negatively its object to be impossible, if it is contradictory, but as we shall see, for Kant more than analysis is needed for positively demonstrating possibility.)
} 
while abstracting from all relation to possible objects, cannot offer criteria for material truth, but only for formal truth. ${ }^{11}$ Accordingly, the task of considering material truth Kant appoints to transcendental logic. ${ }^{12}$ Kant further explicates that "general logic, considered as an organon, [...] teaches us nothing at all about the content of cognition" and is "entirely indifferent with regard to the objects" $" 13$. In other words, general logic alone, contra many a rationalist, cannot be used to derive metaphysical results. For that transcendental logic, which takes the possible object into account, is required as well. Now, one may accordingly say that the above distinction between judgmental modality, that in itself concerns merely formal truth, and categorical modality, that adds the possible existence of the object, corresponds to the distinction between general and transcendental logic. Indeed, judgmental and categorical modality are exactly the two modalities that Kant in the opening quote dubbed logical and transcendental [explicate?]. As I will show later, this distinction between logical and transcendental modality is crucial to Kant's critique of metaphysics. However, let us first take a closer look at the two species of modality.

\section{The Criteria of Modality}

In Jäsche Logik Kant gives the following criteria for the modality of judgments:

1. the principle of contradiction and of identity [...], through which the internal possibility of a cognition is determined for problematic judgments;

2. the principle of sufficient reason [...], on which rests the (logical) actuality of a cognition, the fact that it is grounded, as material for assertoric judgments;

3. the principle of the excluded middle [...], on which the (logical) necessity of a cognition is grounded - that we must necessarily judge thus and not otherwise, i.e., that the opposite is false - for apodeictic judgments. ${ }^{14}$

As we have seen, these criteria are merely formal or logical and do not, as such, concern the existence of the objects of which the judgment is about. ${ }^{15}$ Thus, these criteria hold regardless of whether the judgment is about existing real objects or not.

\footnotetext{
$11 \mathrm{KrV}$, A 55/B 79, A 58-59/B 83.

$12 \mathrm{KrV}$, A 62/B 87.

$13 \mathrm{KrV}$, A 61/B 86.

${ }^{14} \log$, AA 9: 52f.

$15 \mathrm{KrV}$, A 75-76/B 100; Log, AA 9: 50-53.
} 
According to these criteria, then, a judgment is logically possibly true simply insofar as it is selfconsistent. Elsewhere Kant extends this principle also to concepts: a concept is logically possible if it is non-contradictory. ${ }^{16}$ Insofar as a judgment is the only possible choice between two contradictory opposites, it is necessarily true. Consequently, the negation of a contradiction is necessarily true, as we have come to expect. Consider, again, the analytic judgment 'unicorns are one-horned'. The opposite judgment 'unicorns are not one-horned' is, given the standard definition of unicorns, a contradiction. Via the law of excluded middle we must then judge the original judgment 'unicorns are one-horned' to be necessarily true. Finally, we are allowed to say that a judgment is logically true if it is logically grounded, that is, if it follows from true judgments and does not have false consequences. ${ }^{17}$ In purely logical contexts (and hence with regard to merely formal truth) this principle seems to have little use, as there is no room for contingency in logic: any true judgment in logic must be apodictic. However, if one wishes to use logic to infer judgments about reality instead of basing their truth on perception, this criterion is of obvious importance: it determines the criteria for logically deriving consequences and grounds of judgments.

When it comes to material truth about reality, existence and thus another set of criteria must also be considered. These criteria Kant offers in the Critique of Pure Reason, in the section called Postulates of empirical thinking in general (Postulates for short):

1. Whatever agrees with the formal conditions of experience (in accordance with intuition and concepts) is possible.

2. That which is connected [zusammenhängt] with the material conditions of experience (of sensation) is actual.

3. That whose connection [Zusammenhang] with the actual is determined in accordance with general conditions of experience is (exists) necessarily. ${ }^{18}$

These postulates, then, set the criteria according to which we are justified in claiming that an object of our concept exists, i.e., that the concept possibly refers, does refer or even necessarily refers to a real object. This is always done in conjunction with judgmental modality: in addition to formally determining the possible truth of a judgment, one must also materially determine the possible existence of the objects of this judgment. Even though the postulates themselves are quite

\footnotetext{
16 E.g. KrV, A 220/B 267-268.

${ }^{17} \log$, AA 9: $51 \mathrm{f}$.

$18 \mathrm{KrV}$, A 218/B 265-266.
} 
interesting, in the scope of this survey I can offer only very brief explications of them before turning to the more general features and implications of the postulates.

To those familiar with Kant's philosophy the postulate of possibility seems unsurprising: there are conditions for experience, and only such objects that fulfil these conditions are possible. The conditions in question are of course space-time for intuition of objects and categories for concepts of them. More interesting is the example Kant gives. According to him there is no contradiction in the concept of a two-angle, that is, a figure enclosed between two straight lines, and it is on this account logically possible, yet such a figure is impossible because it is in conflict with the properties of space. ${ }^{19}$ In other words, Kant affirms the logical possibility of non-Euclidian figures, yet denies their real possibility. If Kant is right, this goes far in justifying his two modal criteria: that something fulfils the criteria of logical possibility does not yet demonstrate its real possibility. Thus the two sets of criteria are required. ${ }^{20}$

The postulate of actuality is alarmingly reminiscent of Berkeley's esse est percipi, but there is also an all-important difference: not only that which is immediately perceived exists, but also that which is lawfully, i.e. causally mediately connected with something perceived. ${ }^{21}$ As an example of the latter Kant offers magnetism, the existence of which can be deduced from its effects even though it itself is imperceptible to our sense organs. ${ }^{22}$

The postulate of necessity is no doubt of particular interest. Here Kant offers a disappointment: there are no absolutely necessary beings. ${ }^{23}$ No entity can on its own fulfil the criterion of necessity. As a small consolation Kant offers conditional necessity, that from the existence of a cause one can deduce the existence of its effect. ${ }^{24}$ When some material is given to our sensibility, one can, via causality, deduce that something else must also exist. Here it is important to remember that, similarly to the postulate of possibility, the necessity of a concept is again not to be confused with the necessity of its object. This is most prominent in the case of the ideas of pure reason, the concepts of which are necessary while their objects are not.

\footnotetext{
${ }^{19} \mathrm{KrV}$, A 220-221/B 268.

20 The same point is also made repeatedly in the Dialectic, especially in connection to the Transcendental Ideal: KrV, A 594-602/B 626-630. See in particular KrV, A 596n/B 624n and KrV, A 610/B 638.

$21 \mathrm{KrV}$, A 225/B 272.

${ }^{22} \mathrm{KrV}$, A 226/B 273.

${ }^{23} \mathrm{KrV}$, A 226-227/B 279-280.

${ }^{24} \mathrm{KrV}$, A 226/B 280.
} 
Arguably, the Postulates have far-reaching consequences for Kant's system as a whole, particularly for his critique of metaphysics. According to them, the categories are applicable only to (possible) intuition. Indeed, Kant's famous claim that the categories are only of empirical use is finalised in the Postulates, where he states that: "[T]he principles of modality are [...] restrictions of all categories to merely empirical use, without any permission and allowance for their transcendental use ${ }^{\prime 25}$. Thus the ontology described by the categories pertains only to appearances, which are given to us in intuition. That this claim would be finalised in the Postulates may be quite surprising, as Kant could be seen as already having established the result, either in the Transcendental Aesthetic or then at least in the Transcendental Deduction. As concerns the first point, in fact the Aesthetic only aims to show that one cannot intuit anything non-spatiotemporal, not yet that one could not cognise such things (by other means).

What comes to the latter point, there seems to be a genuine problem here, for already in the Schematism Kant says for example that "we have seen [in the deduction of the categories] that concepts are entirely impossible, and cannot have any significance, where an object is not given [in intuition] $]^{\prime 26}$. It is questionable if the Deduction actually establishes such a result, or if it only shows that one is justified in applying the categories to intuitions, not that one would not be justified in applying them outside intuitions. ${ }^{27} \mathrm{Be}$ it as it may, the Postulates nonetheless offer two important additions. First, they determine the exact limits of applying the categories. One could say that earlier Kant may have constructed his system of ontology, but only via the Postulates we finally acquire the criteria that allow us to say that exactly this and no other possible ontological system in fact represents the structure of reality. Second, the Postulates expand on the view that the categories are only applicable to objects given in intuition by stating that these limits of possible experience denote at the same time the limits of possible existence. It is instructive to compare this to Kant's contention that "The a priori conditions of a possible experience in general are at the same time conditions of the possibility of the objects of experience" ${ }^{, 2}$. It is not just that we cannot have an ontology of things in themselves, but that we cannot even properly say that they exist in the strictest sense of the word. If they can be said to be, then their being is different from the existence we are acquainted with. Whether the postulates of practical reason contest this point,

\footnotetext{
$25 \mathrm{KrV}$, A 219/B 266.

${ }^{26} \mathrm{KrV}, \mathrm{A} 139 / \mathrm{B} 178$.

27 Consider in particular KrV, A 89-90/B 122.

${ }^{28} \mathrm{KrV}, \mathrm{A} 111$.
} 
restrict it to theoretical considerations or offer a different notion of existence, is surely an important problem, but it cannot be addressed here.

There is a peculiarity to Kant's view of modality that needs to be sorted out. Kant states that categorical modality is subjective in the sense that it does not "in the least augment the concept [... so] as to add something [hinzusetzen] to the representation of the object" ${ }^{\prime 29}$. This seems to fit poorly to the idea that categorical modality concerns things and their existence - something that seems quite objective. While Kant sometimes uses the term "subjective" to mean something private, such as sensations, modality is not subjective in this sense. Instead, modality is subjective in the sense that for example existence does not add anything to an object, but instead posits it. As Kant clarifies: "Through the actuality of a thing I certainly posit more than possibility, but not in the thing; for that can never contain more in actuality than what was contained in its complete possibility" ${ }^{\prime 3}$. In other words, existing unicorns are the exact same unicorns as the possible ones, merely with different existential status.

According to Kant's somewhat confusing view, modality does nonetheless add something to the object, namely a connection to our subjective faculties. Kant explains that the modal concepts "add to [hinzufügen] the concept of a thing [...] the cognitive power whence it arises and has its seat", and that "the principles of modality [...] do not assert of a concept anything other than the action of the cognitive faculty through which it is generated"31. Thus, modality does not add anything into (augment) the thing, but adds to it (joins it to) the faculty of origin of its concept. Instead of directly asking how our concept refers to objects, Kant takes the concept of an object and asks: How did we come to have it? Here it is useful to remind oneself of Kant's philosophical approach to take our subjective experience of an organised world for granted and to reflect on the necessary conditions for there to be such an experience to begin with. True to his ways, then, Kant takes us to already be in possession of a myriad of concepts that purport to refer to objects. But we must ask: How did we come for instance to have the concept of a unicorn? Have we perhaps only made it up in our understanding and imagination (possibility), have we acquired it via perception (actuality) or is it a kind of a logical demand of reason (necessity)? This way one can grasp the sense of Kant's peculiar view that modality determines the relationship of a representation to the subjective faculties of cognition. After all, it matters little whether we take our thoughts and try to connect them with objects or take the given objects and connect them to our thinking - in both

\footnotetext{
${ }^{29} \mathrm{KrV}$, A 233/B 286.

${ }^{30} \mathrm{KrV}$, A 234-235n/B 287n.

${ }^{31} \mathrm{KrV}$, A 234/B 286-287.
} 
cases thinking and objects become connected. Except that in accordance with his Copernican Revolution, with the latter direction Kant can accomplish what the former never could. So, we can say that for Kant modality is both subjective and objective, as it connects the subject to the object.

\section{Modality and Metaphysics}

It could be said that after setting the bounds of his ontology in the Analytic, in the Dialectic Kant goes on to consider that which is left outside the boundaries. Interestingly, while the Analytic more or less ends with modality, i.e., with the criteria for applying Kant's ontological framework, the Dialectic accordingly begins with modality. [Revise!] In the very first pages of the Dialectic Kant reminds us of the claim in the Postulates that the boundaries of his ontology are set by restricting the principles of understanding to empirical, not transcendental use. ${ }^{32}$ He then goes on to explain that there is also another set of principles that he calls transcendent, which "incite us to tear down all those boundary posts and to lay claim to a wholly new territory that recognizes no demarcations anywhere"33. Kant's point is that while the results of the Analytic for the understanding stand as they are, via the principles of reason one might find a way to overthrow these boundaries and establish a boundless metaphysics, $a ́$ la dogmatic metaphysics.

According to Kant, of course, this attempt to establish transcendent principles is doomed to fail. What is not so obvious, however, is the role modality plays in this. This is best explained by showing what Kant could not accomplish in the Dialectic without his theory of modality. Now, even though Kant's argumentation in the Dialectic is complex, it has a relatively simple core. Arguably, his criticism of the dialectical inferences is directed at their incapacity to demonstrate the existence of the objects they are about, namely the soul, the world as totality and God as the most real being. Kant even states that the dialectical inferences, as transcendental illusions, are on some level necessary and logically valid - it is just that they are insufficient as tenets of metaphysics, since they fail to show that there actually exist any objects corresponding to the ideas of pure reason. [REF.] Pointing out this failure would be impossible, however, were Kant not in possession of the criteria of existence. These criteria, in turn, are offered in the Postulates, as definitions of the modal categories.

\footnotetext{
$32 \mathrm{KrV}$, A 295-296/B 352-353.

$33 \mathrm{KrV}$, A $296 /$ B 352.
} 
In essence, then, Kant can apply his modal theory, first, to mark the bounds of acceptable ontology, and, second, to point out that the ideas of pure reason are not valid metaphysical concepts because they do not fulfil the required existential criteria. Thus, it is only because he has presented the criteria for possible existence that Kant can first of all diagnose that the paralogisms fail to show that there exists an object corresponding to the idea of soul. ${ }^{34}$ This failure is based on the impossibility of giving such an object in intuition. ${ }^{35}$ Secondly and analogously, the resolution of the antinomies rests on distinguishing between the logical requirement for a totality and the ontological impossibility of the existence of such a totality. ${ }^{36}$ The latter part rests, again, on the impossibility of such a totality being given in intuition, and hence it cannot fulfil the existential criteria set by the Postulates. ${ }^{37}$ Finally, the ideal of pure reason fails to offer metaphysical results because the idea of the most real being cannot be connected to any existing object. [REF.] Thus if Kant could not rely on his criteria of possible existence, the arguments in the Dialectic would lose an essential component. One could also say that the speculative metaphysician does not according to Kant commit any logical fallacy but instead makes an illegitimate transcendental assumption of possible existence.

There is, however, also another side to the Dialectic, namely Kant's claim that transcendental illusion is nonetheless unavoidable. As Kant explains, the illusion is born when "the subjective necessity of a certain connection of our concepts on behalf of the understanding is taken for an

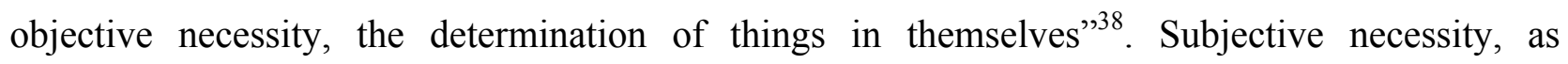
concerning the connection of concepts, falls under judgmental modality, whereas objective necessity, as having a reference to things, requires also categorical modality. Now, what is correct here is that the ideas of pure reason are indeed subjectively necessary as regulative principles of reason, that is, as ideas directing our use of the understanding. ${ }^{39}$ The ideas are necessary because they are, according to Kant, necessary elements of thinking. This shows, however, only that they fulfil the criteria of judgmental modality of thinking, and it would be an error to take them objectively as referring to objects, as it has not yet been shown that they fulfil the criteria of categorical modality. Arguably, then, the error in the Dialectic comes about when one fails to notice the additional criteria of the existence of objects, and so in effect takes the subjective logical

\footnotetext{
${ }^{34} \mathrm{KrV}, \mathrm{B} 411$, B 411-412n.

35 E.g. KrV, B 429-432.

${ }^{36} \mathrm{KrV}$, A 499-501/B 527-529.

$37 \mathrm{KrV}$, A 504/B 533.

${ }^{38} \mathrm{KrV}$, A 297/B 353.

${ }^{39} \mathrm{KrV}$, A 642-644/B 670-672.
} 
necessity of the ideas of reason as necessary existence of the objects corresponding to these ideas. Furthermore, it is exactly because Kant has a dual-layer theory of modality that he has room for such ideas that are simultaneously impossible on the one hand and necessary on the other.

To wrap it up, the ideas of pure reason are necessary for thinking, yet their objects cannot be shown to be possible - if not always impossible either. The former is based on the criteria of judgmental modality, the latter on the criteria of categorical modality. One could say that Kant's point in the Dialectic is that no matter how much one tries to wiggle around it by engaging in complex logical jugglery, the ideas of pure reason simply lack reference to existence. They lack it because, when trying to overcome the restrictions set for the understanding in the Postulates, the ideas also detach themselves from existence, the criteria of which the exact same Postulates lay down. This is, then, the modal view to Kant's logic of illusion: by not noticing the two criteria of modality, the metaphysicians have confused the merely logical kind of necessity of the ideas with the objective existence of their objects. [Analyticity?] What is equally important is that Kant's analysis of modality can even today be applied against such thinkers as David Lewis or Alvin Plantinga that have attempted to derive properly metaphysical results from mere logical analysis of modality. Thus Kant would claim that these philosophers too fall into the same deceptive trap of inexperience as his predecessors, namely to the "deception of substituting the logical possibility of the concept $[\ldots]$ for the transcendental possibility of things" $"$.

\section{Summary and Conclusion}

I hope to have shown, first, that there is such a thing that might be labelled Kant's theory of modality, and, second, that it offers an interesting and useful new approach to his critique of metaphysics. According to this theory there are two layers of modality, one concerning truth of judgments and the other concerning existence of things. These two modalities have different criteria. Only such judgments that fulfil both criteria of necessity can be considered part of justified ontology. The main idea of Kant's critique of metaphysics is, then, that there are judgments that fulfil the logical criteria of necessarily true judgments yet, contrary to their appearance, fail to fulfil the transcendental criteria of necessarily existent objects - and thus they fail to produce justified metaphysics. While we are not normally misled by for instance analytic judgments, in the case of the three ideas of pure reason we are compelled to assume the existence of their objects. It is for this reason that the existential criteria of the categorical modality are so

\footnotetext{
${ }^{40} \mathrm{KrV}$, A $244 / \mathrm{B} 302$.
} 
important: they equip Kant, perhaps for the first time in the history of philosophy, with clear criteria and hence tools for justifying existential claims, and, in effect, allow him to show that in the case of several important metaphysical concepts these criteria are not and cannot be met. In this sense, Kant's revolutionary view on modality is one of the driving forces of his critique of metaphysics. 